\title{
Cone Beam CT for Sinus lmaging
}

Mr Rishi Shukla ${ }^{1}$, Mr Bidemi Alli ${ }^{1}$, Mr Deepak Gupta ${ }^{2}$

1) Specialist Registrar ENT Surgery, 2) Consultant Rhinologist/ENT Surgeon

Back:[ound

Sinus imaging provides anatomical and pathological information. Many hospitals have cone beam CT (CBCT) facilities which allow imaging with reduced radiation and waiting times. Can using this increase productivity?

\section{Objectives}

Utilise walk in cone beam CT service to provide sinus imaging during the same clinical appointment.

\section{Methods}

CBCT for sinus imaging via oral surgery was used for patients seen in the ENT department. Calculation of cost saving for appointments and scanning were compared.

\section{Resultis}

Utilising CBCT directly during outpatient appointment was associated with a reduction in the number of returns to hospital and CT slots via radiology. In addition, patients who would benefit from operative intervention were identified early and added to the waiting list.

\section{Conchusion}

CBCT provides detailed images with lower radiation exposure and immediate image availability. Using existing equipment to increase productivity improves cost. It is something all NHS trusts with availability should consider.

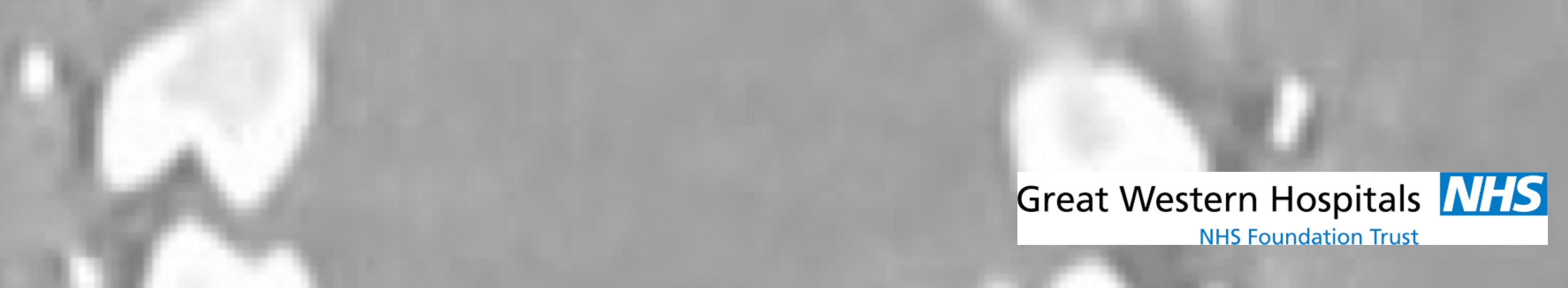

